\title{
Author Correction: Critical Shear Stress is Associated with Diabetic Kidney Disease in Patients with Type 2 Diabetes
}

\author{
Seung Min Chung ${ }^{1}$, Jung Hyun $\mathrm{Oh}^{2}$, Jun Sung Moon ${ }^{1}$, Yu Kyung Kim³ ${ }^{3}$ Ji Sung Yoon ${ }^{1}$, \\ Kyu Chang Won ${ }^{1}$ \& Hyoung Woo Lee ${ }^{1}$
}

Correction to: Scientific Reports https://doi.org/10.1038/s41598-018-19274-5, published online 17 January 2018

In the original version of this Article, Affiliation 3 was incorrectly listed as 'Department of Clinical Pathology, Kyungpook National University School of Medicine, Daegu, Republic of Korea.' The correct affiliation is listed below:

Department of Clinical Pathology, School of Medicine, Kyungpook National University, Daegu, Republic of Korea.

This error has now been corrected in the PDF and HTML versions of the Article.

(i) Open Access This article is licensed under a Creative Commons Attribution 4.0 International License, which permits use, sharing, adaptation, distribution and reproduction in any medium or format, as long as you give appropriate credit to the original author(s) and the source, provide a link to the Creative Commons license, and indicate if changes were made. The images or other third party material in this article are included in the article's Creative Commons license, unless indicated otherwise in a credit line to the material. If material is not included in the article's Creative Commons license and your intended use is not permitted by statutory regulation or exceeds the permitted use, you will need to obtain permission directly from the copyright holder. To view a copy of this license, visit http://creativecommons.org/licenses/by/4.0/.

(C) The Author(s) 2018

\footnotetext{
${ }^{1}$ Division of Endocrinology and Metabolism, Department of Internal Medicine, Yeungnam College of Medicine, Daegu, Republic of Korea. ${ }^{2}$ Kwon and Oh Internal Medicine, Sangju, Gyeongbuk, Republic of Korea. ${ }^{3}$ Department of Clinical Pathology, School of Medicine, Kyungpook National University, Daegu, Republic of Korea. Seung Min Chung and Jung Hyun Oh contributed equally to this work. Correspondence and requests for materials should be addressed to J.S.M. (email: mjs7912@yu.ac.kr)
} 